\title{
SABERES E DIREITOS DESCOLONIZADOS: A CONTRIBUIÇÃO DA \\ CATEGORIA RAÇA E A REINVENÇÃO DOS DIREITOS A PARTIR DE \\ UMA EPISTEMOLOGIA LATINO-AMERICANA
}

\author{
DECOLONIALIZED KNOWLEDGES AND RIGHTS: THE CONTRIBUTION OF
}

\author{
RACIAL CATEGORY AND THE RE-INVENTION OF RIGHTS FROM A LATIN
}

AMERICAN EPISTEMOLOGY

Recebido em 15/12/2017

Aprovado em 20/04/2018

\section{PAULO FERNANDO SOARES PEREIRA ${ }^{1}$}

ANA CLAUDIA FARRANHA ${ }^{2}$

\begin{abstract}
RESUMO: O artigo pretende analisar, em uma perspectiva decolonial, como uma epistemologia latino-americana pode inaugurar novas perspectivas jurídicas para a construção de novos direitos. Sem desconsiderar alguns estudos da epistemologia crítica do "Norte", o trabalho, a partir de uma epistemologia do "Sul", analisa como têm sido enfrentadas as questões dos novos direitos constitucionais na América Latina, partindo do pressuposto segundo o qual a questão racial é um dos elementos fundamentais para a compreensão do processo de dominação inaugurado pela Modernidade. A metodologia consistiu na revisão crítica da literatura e o trabalho é dividido em duas partes: a) o colonialismo, o racismo e a tomada de consciência de sujeitos renegados; b) Saberes e direitos descolonizados: a reinvenção dos direitos a partir de uma epistemologia latino-americana.
\end{abstract}

PALAVRAS-CHAVE: Colonialismo e racismo; sujeitos renegados e tomada de consciência; novos direitos e América Latina.

ABSTRACT: The paper aims to analyze, by a decolonizing perspective, how the Latin American epistemology may inaugurate new juridical perspectives in order to build up new rights. The article examines, from a Southern epistemology, how the questions of new rights in Latin America have been faced, without ignoring some studies of the critical Northern epistemology, assuming that the racial question is one of the fundamental elements in order to understand the process of domination unveiled by Modernity. The methodology is based on a critical review of literature and the work has been divided in two parts: a) the colonialism, the racism and the awareness of renegade individuals; b) decolonialized knowledges and rights: the re-invention of rights from a Latin American epistemology.

KEY-WORDS: Colonialism and racism; renegade individuals and awareness; new rights and Latin America.

\footnotetext{
1 Doutorando em Direito pela Universidade de Brasília - UnB. Mestrado em Direito e Instituições do Sistema de Justiça pela Universidade Federal do Maranhão - UFMA. Membro da Advocacia-Geral da União - AGU (Procurador Federal). Integrante do Grupo de Estudo GEOP - Observatório de Políticas Públicas: estudos territoriais e equidade e do MARÉ - Núcleo de Estudos e Pesquisas em Cultura Jurídica Atlântico Negro.

2 Professora Permanente do Programa de Pós-Graduação em Direito da Universidade de Brasília (FD/UnB). Doutorado em Ciências Sociais pela Universidade Estadual de Campinas - UNICAMP. Mestrado em Ciência Política pela Universidade Estadual de Campinas - UNICAMP. Coordenadora do Grupo de Estudo GEOP Observatório de Políticas Públicas: estudos territoriais e equidade.
} 


\section{INTRODUÇÃO}

$\mathrm{O}$ artigo tem por objetivo analisar, em uma perspectiva decolonial, como uma epistemologia latino-americana pode inaugurar novas perspectivas jurídicas para a construção de novos direitos constitucionais. Assim, sem desconsiderar alguns dos estudos da epistemologia crítica do "Norte", o trabalho, a partir de uma epistemologia do "Sul", analisa como têm sido enfrentadas as questões dos novos direitos na América Latina, partindo do pressuposto segundo o qual a questão racial é um dos elementos fundamentais para a compreensão do processo de dominação inaugurado pela Modernidade.

Inicialmente, o artigo procura relacionar a questão da Modernidade, o colonialismo e o racismo como uma tríade que deve continuar a ser tratada pelas Ciências Sociais, a fim de que os sujeitos renegados possam tomar consciência desse processo, proporcionando a construção de novos direitos, efetivamente, relacionados com a historicidade e realidade dessa parte do continente americano. Em seguida, o artigo aborda a questão dos saberes e direitos descolonizados, abordando como se pode realizar a hipótese levantada no parágrafo anterior. Para se reinventar direitos, há necessidade de se ter uma epistemologia latino-americana, que não seja mero receptáculo de teorias que não se amoldam à realidade dos sujeitos encobertos pela Modernidade.

A metodologia consistiu na revisão crítica da literatura e o trabalho é dividido em duas partes: a) o colonialismo, o racismo e a tomada de consciência de sujeitos renegados; b) Saberes e direitos descolonizados: a reinvenção dos direitos a partir de uma epistemologia latino-americana.

\section{O COLOnialismo, O RACISMO E A TOMADA DE CONSCIÊNCIA DE SUJEITOS RENEGADOS}

O colonialismo e o racismo podem ser considerados como expressões da estrutura de dominação decorrente da Modernidade, pois havia necessidade de que fossem criadas 
distinções entre os humanos capazes de sustentar as diferenças econômicas 3: a criação de teorias jurídicas para sustentar tal empreitada foi essencial.

Do próprio Norte, surgiram questionamentos a respeito do processo de colonização levado adiante, por séculos, pela Europa. Um exemplo contundente e controverso foi, em França, o desempenhado por Jean-Paul Sartre, para quem o colonialismo rejeitou os direitos humanos para os homens e mulheres que ele submeteu pela violência, cuja conservação se deu pela força da miséria, da ignorância e de um estado de sub-humanidade; para que se mantivesse como sistema econômico, era essencial ao colonialismo a prática do racismo, inscrito nos próprios fatos, nas instituições, na natureza das trocas e da produção; os estatutos político e social se reforçavam mutuamente, dando feição sub-humana aos dominados (negros e indígenas), já que as declarações de direitos não lhes diziam respeito; dessa maneira, de forma inversa, se não tinham direitos, os dominados eram abandonados sem proteção às forças desumanas da natureza, às leis da economia (SARTRE, 1968b), ou seja, totalmente alheios dos benefícios das revoluções burguesas (liberté, égualité et fraternité seriam direitos que lhes seriam constantemente renegados), estabelecendo-se uma ordem de direitos universais para todos os seres humanos como uma forma exatamente para negar direitos à maioria deles (LANDER, 2005).

Para Jean-Paul Sartre, foi com a presença efetiva de parte de sua força armada que o colonizador interferiu contraditoriamente seu discurso 'civilizador', instaurando o domínio e a exploração sobre a grande maioria da população, com base no uso da força, na imposição cultural, na inquirição de elementos exóticos e na intimidação pelo fogo lançado dos fuzis, símbolo maior de uma suposta superioridade científica, tecnológica, econômica e cultural; usou-se a força como instrumento de superioridade cultural, objetivando mudar ancestrais padrões de uma sociedade tribal e para a imposição do trabalho forçado; os nativos africanos,

\footnotetext{
3 “As categorias, conceitos e perspectivas (economia, Estado, sociedade civil, mercado, classes, etc.) se convertem, assim, não apenas em categorias universais para a análise de qualquer realidade, mas também em proposições normativas que definem o dever ser para todos os povos do planeta. Estes conhecimentos convertem-se, assim, nos padrões a partir dos quais se podem analisar e detectar as carências, os atrasos, os freios e impactos perversos que se dão como produto do primitivo ou o tradicional em todas as outras sociedades. Esta é uma construção eurocêntrica, que pensa e organiza a totalidade do tempo e do espaço para toda a humanidade do ponto de vista de sua própria experiência, colocando sua especificidade histórico-cultural como padrão de referência superior e universal. Mas é ainda mais que isso. Este metarrelato da modernidade é um dispositivo de conhecimento colonial e imperial em que se articula essa totalidade de povos, tempo e espaço como parte da organização colonial/imperial do mundo. Uma forma de organização e de ser da sociedade transforma-se mediante este dispositivo colonizador do conhecimento na forma "normal" do ser humano e da sociedade. As outras formas de ser, as outras formas de organização da sociedade, as outras formas de conhecimento, são transformadas não só em diferentes, mas em carentes, arcaicas, primitivas, tradicionais, pré-modernas" (LANDER, 2005, p. 34).
} 
diziam os colonizadores evolucionistas, seriam os ditos animais em estado de evolução, seriam os seres que um dia o colonizador teria sido, no passado (ARANTES, 2011), devendo o colonizador, com seu ego altruísta, ajudar tais povos a superar tal estado de atraso e “incivilização", pautando-se a ordem constitucional vigente em um modelo liberal de igualdade que ocultava o reconhecimento dos sujeitos negros indígenas. Portanto, a pergunta que aparece é: tal ordem é capaz de efetivar garantias e direitos fundamentais?

Nesse contexto, o racismo, engendrado pelo aparelho de dominação colonial, foi mantido pelas relações de produção que definiram duas espécies de sujeitos: para uns, privilégios e a humanidade, homens livres no exercício de seus direitos; para demais, "os outros", a ausência de direitos e a sanção pela miséria, a fome crônica, a ignorância e a subhumanidade (SARTRE, 1968b).

A visão de Jean-Paul Sartre sobre o racismo imperialista europeu de conquistas, as guerras e dominações coloniais, sobre as práticas de intolerância, exploração e humilhação dos povos subjugados, assim como sua crítica sobre uma forma nacional francesa de tradições racistas, que teria se desdobrado na colonização, era uma tentativa de convencer outros intelectuais franceses de que o neocolonialismo seria uma realidade que não poderia ser tratada com indiferença; para o filósofo, o colonizador que escraviza outro homem como se fosse um pedaço de carvão ${ }^{4}$, facilmente substituível por um sangue novo negro, carregaria em seu ser uma ânsia de exploração e espoliação das riquezas naturais, sem limites; para o colonizador, o importante era espoliar as riquezas tropicais das colônias para serem transformadas em manufaturas na metrópole, não importando o homem cultural, dotado de sentimentos, de língua, de religiosidade, mas apenas sua força, sua mão-de-obra a serviço da nação colonizadora (ARANTES, 2011).

Para justificar tal sistema econômico, o racismo foi essencial, pois é uma dessas formas de dominação que pode se disfarçar, podendo ser um elemento chave para se compreender diversas questões de desigualdade presentes nas variadas sociedades. Conquanto seja combatido pela legislação, como no Brasil, atualmente, persistem formas ocultas de

\footnotetext{
4 A metáfora, aqui, é provocativa, já que o "carvão", preto como o negro, quando árvore, teve vida; agora, o negro, à semelhança da arvore que vira carvão, após retirada a sua liberdade, transforma-se em simples objeto de um sistema de produção, servindo apenas como combustível (força de trabalho), sendo que seu destino é se transformar em cinzas.
} 
racismo que acabam sendo acobertadas pelo próprio direito. Isso porque o direito só costuma combater as formas mais explícitas, deixando outras formas sob o manto da normalidade.

Como fenômeno complexo, o racismo pode se dar por variadas formas: individualmente, quando um indivíduo considera que as pessoas negras, como um grupo, são inferiores aos brancos por causa de traços físicos (genotípicos ou fenotípicos), acreditando que tais traços físicos são determinantes de comportamento social, assim como de qualidades morais ou intelectuais; institucionalmente, o racismo pode se dar de forma manifestada ou oculta, quando complexas relações inter-relacionais entre as instituições da sociedade fazem com que os efeitos em longo prazo de uma prática institucional sejam negativos, podendo se manifestar na economia, educação e nos sistemas burocráticos ou de justiça; pode se manifestar, ainda, na forma cultural $^{\text {, }}$, definindo-se como expressão individual e institucional da superioridade da herança cultural de uma raça em relação à outra (JONES, 1973). Sobre a última forma, a cultural, Frantz Fanon (2008, p. 34) advertia:

Todo povo colonizado - isto é, todo povo no seio do qual nasceu um complexo de inferioridade devido ao sepultamento de sua originalidade cultural - toma posição diante da linguagem da nação civilizadora, isto é, da cultura metropolitana.

Quanto mais assimilar os valores culturais da metrópole, mais o colonizado escapará da sua selva. Quanto mais ele rejeitar sua negridão, seu mato, mais branco será.

Aqui, vale lembrar que Pierre Bourdieu e Löic Wacquant (2005) advertiam que o imperialismo cultural tende a se apoiar sobre o poder de universalizar particularismos ligados a uma tradição histórica singular fazendo com que os mesmos não sejam reconhecidos como tal.

É importante se tratar do racismo cultural porque ele geralmente é uma forma bem engendrada e oculta de dominação, pois o racismo é adequado na medida em que fatores raciais e culturais estão bem correlacionados e constituem uma base sistemática para tratamento de inferioridade; por exemplo, quando, inicialmente, os europeus encontraram os africanos, os dois grupos apresentavam diferenças culturais elementares; as religiões africanas eram predominantemente politeístas e, em sua maioria, utilizavam-se da magia e da

\footnotetext{
${ }^{5}$ Um exemplo adequado é dado por Enrique Dussel (1993, p. 52): ““coloniza-se’ a sexualidade índia, ofende-se a erótica hispânica, instaura-se a moral dupla do machismo: dominação sexual da índia e respeito puramente aparente pela mulher europeia. Dali nasce o filho bastardo (o 'mestiço', o latino-americano, fruto do conquistador e a índia) e o crioulo (o branco nascido no mundo colonial de Índias)".
} 
"superstição"; as religiões europeias, por outro lado, eram monoteístas e acentuavam o pensamento racional, afirmado pela Modernidade (JONES, 1973).

No ponto acima, um dos elementos de dominação colonial residiu na dominação dos elementos culturais dos povos dominados, principalmente, nos campos religiosos e da educação. No campo religioso, tal dominação costumou se dar por meio da supressão dos cultos nativos e estabelecimento do cristianismo como religião oficial, estímulo para que os não cristãos se convertessem, afirmação ou estímulo da ordem existente (caso atípico da colonização onde o islã predominava); já no campo educacional, nas Américas, o Espanhol, o Português, o Inglês e o Francês se tornaram línguas obrigatórias, combatendo-se as línguas indígenas (OSTERHAMMEL, 2005).

Como em qualquer processo de dominação, o primeiro passo para subverter tal situação é que os sujeitos oprimidos tomem consciência desse processo de dominação. Como advertia Jean-Paul Sartre (1968, p. 93), ao tratar sobre o racismo, “[...] não resta dúvida de que a classe oprimida deve primeiro tomar consciência de si mesma. Mas esta tomada de consciência é exatamente o contrário de uma reimersão em si: trata-se de reconhecer, na ação e pela ação, a conjuntura objetiva do proletariado que pode definir-se através das circunstâncias de produção ou da repartição de bens”. Essa tomada de consciência é essencial porque:

O negro não pode negar que seja negro ou reclamar para si esta abstrata humanidade incolor: ele é preto. Está pois encurralado na autenticidade: insultado, avassalado, reergue-se, apanha a palavra 'preto' que lhe atiram qual uma pedra; reivindica-se como negro perante o branco, na altivez. A unidade final, que aproximará a todos os oprimidos no mesmo combate, deve ser precedida nas colônias por isso que eu chamaria momento da separação ou da negatividade: este racismo antirracista é o único caminho capaz de levar à abolição das diferenças de raça (SARTRE, 1968, p. 94).

Para ser reconhecido é preciso ser afirmado e, antes de tudo, auto reconhecer-se. Em 1968, ao questionar o sistema de neocolonial francês, Jean-Paul Sartre (1968b, p. 140) já advertia que:

Enfim, o Terceiro Mundo se descobre e se fala por esta voz. Sabe-se que ele não é homogêneo e nele ainda se encontram povos escravizados, outros que adquiriram uma falsa independência, outros que se batem para conquistar a soberania, outros, finalmente, que conseguiram a plena liberdade mas que vivem sob a ameaça constante de uma agressão imperialista. Essas diferenças nasceram da história colonial, o que quer dizer da opressão. Aqui a Metrópole se contentou em pagar alguns senhores feudais: ali, dividindo para reinar, fabricou com todas as peças uma burguesia de colonizados; mais além realizou um golpe duplo: a colônia é ao mesmo tempo de exploração e 
de povoamento. Assim, a Europa multiplicou as divisões, a oposições, forjou classes e às vezes racismos, tentou através de todos os expedientes provocar e aumentar a estratificação das sociedades colonizadas.

$\mathrm{Na}$ perspectiva sartriana, os povos negros foram desumanizados, como nativos colonizados ou negros deportados e o encontro com sua humanidade perdida só será possível quando a palavra "preto" for recuperada diante do branco e quando for reconhecido como homem preto que é; portanto, por ser um sujeito oprimido em sua raça, é dela que deve tomar consciência (ARANTES, 2011), já que foram excluídos da comunidade de comunicação hegemônica inaugurada pela Modernidade. Em uma perspectiva epistemológica do Sul, Aníbal Quijano (2005, p. 228) é bastante enfático ao dizer que:

A ideia de raça, em seu sentido moderno, não tem história conhecida antes da América. Talvez se tenha originado como referência às diferenças fenotípicas entre conquistadores e conquistados, mas o que importa é que desde muito cedo foi construída como referência a supostas estruturas biológicas diferenciais entre esses grupos. [...] Na América, a ideia de raça foi uma maneira de outorgar legitimidade às relações de dominação impostas pela conquista. A posterior constituição da Europa como nova identidade depois da América e a expansão do colonialismo europeu ao resto do mundo conduziram à elaboração da perspectiva eurocêntrica do conhecimento e com ela à elaboração teórica da ideia de raça como naturalização dessas relações coloniais de dominação entre europeus e não europeus. Historicamente, isso significou uma nova maneira de legitimar as já antigas ideias e práticas de relações de superioridade/inferioridade entre dominantes e dominados. Desde então demonstrou ser o mais eficaz e durável instrumento de dominação social universal, pois dele passou a depender outro igualmente universal, no entanto mais antigo, o intersexual ou de gênero: os povos conquistados e dominados foram postos numa situação natural de inferioridade, e consequentemente também seus traços fenotípicos, bem como suas descobertas mentais e culturais. Desse modo, raça converteu-se no primeiro critério fundamental para a distribuição da população mundial nos níveis, lugares e papéis na estrutura de poder da nova sociedade. Em outras palavras, no modo básico de classificação social universal da população mundial.

Essa invasão e a subsequente colonização acabaram por excluir da comunidade de comunicação hegemônica muitos 'rostos', sujeitos históricos, os oprimidos, que constituem a "outra face" da Modernidade; os outros en-cobertos pelo des-cobrimento, os oprimidos das nações periféricas, sofredores de uma dupla dominação, são que o se pode considerar como as vítimas inocentes do sacrifício, formando-se como um 'bloco social', em terminologia de Antônio Gramsci, que se constitui como povo, como ‘sujeito histórico’ em certos momentos; como, por exemplo, na emancipação nacional no começo do século XIX (quando a classe dos crioulos, dominados nesta época pelos espanhóis, pela burocracia e pelos grupos comerciais e financeiros peninsulares, lideram os processos das lutas contra Espanha e Portugal; nessa 
emancipação todas as classes dominadas, o 'bloco social dos oprimidos', adquiriu fisionomia de sujeito histórico e realizou uma verdadeira revolução política; posteriormente, durante o transcurso do século XIX, os crioulos passaram, de dominados, a ser os dominadores da nova ordem neocolonial, periférica, cuja classe que mediatiza a dominação externa das metrópoles do capitalismo industrial (DUSSEL, 1993).

Romper com esse paradigma é possível, devendo-se, para tanto, questionar a própria função do conhecimento proporcionado pelas Ciências Sociais, bem como do Estado de Direito, incapaz de atender aos anseios dos sujeitos que ficaram de fora ou não totalmente abrangidos pelo que se denominou de "comunidade de comunicação".

Todavia, como é possível romper com essa lógica de dominação? Como os saberes proporcionados pelas Ciências Sociais podem alicerçar mudanças baseadas em uma sistemática jurídica de reconhecimento e de empoderamento? No caso da América Latina, muitas das respostas não serão encontradas apenas na mera repetição das ideias vindas do Norte, seja da Europa ou dos Estados Unidos. Conquanto não se deva desconsiderar a produção desse conhecimento, deve-se ter em mente que é possível se construir uma epistemologia que envolva a historicidade e a realidade que impera nesta parte do continente.

\section{SABERES E DIREITOS DESCOLONIZADOS: A REINVENÇÃO DOS DIREITOS A PARTIR DE UMA EPISTEMOLOGIA LATINO-AMERICANA}

A atual crise do Estado de Direito levou a uma crise de representação política em todos os níveis, seja em âmbito local, nacional e global, pois muitos sujeitos não têm voz nos espaços para poder manifestar sua vontade, assim como, por diversas vezes, não podem denunciar quando decisões e ações tomadas e realizadas em outras fronteiras afetam suas vidas (ÁVILA SANTAMARÍA, 2011). Nesse cenário, uma parcela elevada dos habitantes da América Latina é constituída por sujeitos que se constituíram como "os outros" da Modernidade, tais como camponeses, trabalhadores urbanos, indígenas e demais povos tradicionais, dentre tantos outros.

Neste sentido, o direito e o Estado colonial do século XXI entraram em crise porque não puderam dar respostas às demandas de eliminação das exclusões, marginalizações e 
discriminações; as instituições ocidentais não somente não puderam dar respostas às novas demandas e àquelas que já estavam reprimidas, mas até fortaleceram um sistema social que costuma promover a assimetria, através de instituições tais como a cidadania, a democracia representativa como única forma de expressão política, os direitos humanos lidos como a chave hegemônica-ocidental, a nação, dentre outras; o custo social e cultural da proposta ocidental é muito alto: a descaracterização, a subordinação e a devastação da natureza (ÁVILA SANTAMARÍA, 2011).

Para a compreensão desse fenômeno, os estudos sobre decolonialidade ${ }^{6}$ têm avançado e a partir dos mesmos têm surgido novas formas de se interpretar a história universal e local, levando-se, por exemplo, à compreensão de determinados fenômenos jurídicos e suas implicações nas estruturas sociais dos países em desenvolvimento, como ocorre na América Latina, especialmente no Brasil, foco deste trabalho.

No caso da América Latina, o pensamento social tem produzido uma ampla gama de buscas, de formas alternativas do conhecimento, questionando-se o caráter colonial/ eurocêntrico dos saberes sociais sobre o continente, o regime de separações que lhes serviram de fundamento e ideia de modernidade como modelo civilizatório universal (LANDER, 2005), vindo à tona questões como gênero e raça, bastante ocultadas pelo processo de dominação.

Romper com um modelo de colonialidade requer uma consciência do papel da ciência, inclusive das Ciências Sociais 7 . Pierre Bourdieu e Löic Wacquant (2005), por exemplo, recordam que a neutralização do contexto histórico resultante da circulação internacional de textos e do correspondente esquecimento de suas condições históricas de origem produz uma aparente universalização ampliada do trabalho de 'teorização'.

6 Dois exemplos de coletâneas com pluralidade de ideais em torno da temática, $c f$. MIGNOLO, Walter D. (Editor). Local histories/global designs: coloniality, subaltern knowledges, and border thinking (2000); REVATHI, Krishnaswamy; HAWLEY, John C. (Editors). The postcolonial and the global (2008).

7 "Na América Latina, as ciências sociais, na medida em que apelaram a esta objetividade universal, contribuíram para a busca, assumida pelas elites latino-americanas ao longo de toda a história deste continente da 'superação' dos traços tradicionais e pré-modernos que têm servido de obstáculo ao progresso e à transformação destas sociedades à imagem e semelhança das sociedades liberais industriais. Ao naturalizar e universalizar as regiões ontológicas da cosmovisão liberal que servem de base a suas constrições disciplinares, as ciências sociais estão impossibilitadas de abordar processos histórico-culturais diferentes daqueles postulados por essa cosmovisão. Caracterizando as expressões culturais como 'tradicionais' ou 'não modernas', como em processo de transição em direção à modernidade, nega-se-lhes toda possiblidade de lógicas culturais ou cosmovisões próprias. Ao colocá-las como expressão do passado, nega-se sua contemporaneidade" (LANDER, 2005, p. 37). 
A compreensão e mudança das relações sociais extremamente desiguais na América Latina requerem conhecimento da história colonial e do processo de dominação que se firmou no continente. Dessa forma, a recuperação coletiva da história, surgida na América Latina, nos fins da década de 70 (setenta), e implementada como corrente de pensamento durante os anos 80 (oitenta) do século XX, construiu-se em um dos antecedentes mais claros na configuração dos cenários políticos e epistêmicos críticos no campo da memória coletiva (CUEVAS MARIN, 2013), representando uma tomada de consciência em torno das estruturas institucionais passadas, a realidade presente e as perspectivas de futuro dessas estruturas.

Catherine Walsh (2013, p. 26) lembra que a memória coletiva, neste sentido, é a que articula a continuidade de uma oposta decolonial, a qual pode ser entendida como um viver de luz e liberdade em meio das trevas; assim, não é de surpreender a aflição dos agentes coloniais de apagar a luz e, por conseguinte, as tentativas de imposição de molduras de racionalidade fundadas em binarismos dicotômicos: homem/natureza, mente/corpo, civilizados/bárbaros, dentre outras, assim como nas ideais de raça e gênero.

Assim, não é possível falar em mudanças sociais sem se pensar em mudanças nas relações jurídicas, forte fator de estruturação da engenharia institucional latino-americana. Qualquer projeto de mudança social, seja com o reconhecimento ou a ampliação de direitos aos grupos tradicionalmente excluídos, deve considerar que as instituições latino-americanas possuem um arcabouço jurídico de proteção de privilégios que remonta ao período colonial e escravagista, devendo-se rememorar a história coletiva do continente, a fim de se ter essa compreensão ${ }^{8}$.

Pilar Cuevas Marín (2013, p. 93), nesse sentido, recorda que a recuperação coletiva da história se organizou a partir dos seguintes aspectos: $a$ ) primeiro surge na América Latina, nos fins da década de 1970 e durante 1980, em resposta ao protagonismo adquirido por setores populares, urbanos e rurais; $b$ ) segundo, esse cenário se encarregou de visibilizar desde os atores protagonistas das demandas sociais e políticas, trajetórias históricas que até esse

\footnotetext{
8 “Poderíamos dizer, então, que o aporte da recuperação coletiva da história ao pensamento crítico latinoamericano o encontramos no questionamento que esta corrente estabeleceu com seus discursos, práticas e atores, em relação às ordens políticas e intelectuais hegemônicos da sociedade e a academia, nos fins das décadas de 1970 a 1980. Devemos a esta corrente de pensamento o surgimento de múltiplas narrativas históricas e suas correspondentes memórias, que foram subalternizadas pelos regimes de poder instaurados na América Latina desde o período colonial; assim mesmo, pelo papel que posteriormente cumprem os saberes modernos, em especial a história, neste processo de subalternização dessas 'outras' memórias históricas" (CUEVAS MARÍN, 2013, p. 94).
} 
momento haviam sido subalternizadas pelas narrativas oficiais da história; c) terceiro, na visibilidade de ditas trajetórias históricas, definiu-se a contribuição teórica e metodológica de experiências e práticas investigativas provenientes da investigação participativa e a educação popular, por uma parte, e da história popular por outra; essas distintas perspectivas, mas em especial a primeira, possibilitaram a emergência da recuperação coletiva da história, entendida como corrente de pensamento; $d$ ) quarto, na corrente de pensamento, a recuperação coletiva da história incorporou, como parte de seus discursos fundacionais, os aportes provenientes da teoria marxista, a filosofia e a teologia da libertação, assim como as investigações participativas e a educação popular.

Com o resgate dessa memória coletiva, ou seja, com essa tomada de consciência histórica, tem sido possível construir alternativas teóricas aos modelos sociais e institucionais que haviam sido naturalizados, inclusive com a retomada de discussões raciais, um forte elemento para a compreensão do processo de desigualdade que se mantém no continente.

A dominação dos sujeitos, acobertada por teorias jurídicas, não foi um processo sem resistência. Houve contínua resistência e luta pelos indígenas 9 e negros, muitas vezes encoberta e negada pela história dominante. No caso dos negros:

\begin{abstract}
A resistência dos escravos foi contínua. Muitos deles alcançaram a liberdade pela luta. Testemunho disso são os "quilombos" no Brasil (territórios libertados, em alguns casos com mulheres de afro-brasileiros que desafiaram durante anos os exércitos coloniais) ou as "costas do Pacífico" na América Central (região do refúgio e liberdade dos escravos britânicos na Jamaica). A ordem escravista-colonial, porém, respondia brutal e sistematicamente a toda tentativa de fuga ou emancipação. Da cultura francesa emanou Le Code Noir ou Recueil des Règlements rendus jusq'a present, uma das expressões mais irracionais da história da humanidade e que sofreram os afrocaribenhos do Haiti, Guadalupe e Martinica durante decênios. Foi um exemplo prototípico do "direito" opressor do mercantilismo capitalista emanado da revolução burguesa moderna: a liberdade da Modernidade "para dentro" (liberdade essencial da pessoa em Hobbes ou Locke) não era contraditório a com a escravidão "para fora" - dupla face do "mito da Modernidade" até 1992, e que a política do Mercado Comum Europeu, que se fecha sobre si, expressa mais uma vez (DUSSEL, 1993, p. 164).
\end{abstract}

Essa negação da história das lutas dos indígenas e negros serviu para retirar a legitimidade das reinvindicações de tais sujeitos, algo que tem sido bastante questionado nas

\footnotetext{
9 “O índio resistirá durante séculos; sua vida cotidiana certamente será afetada de todas as maneiras pelos invasores - mesmo que não seja mais do que pela introdução dos instrumentos de ferro como o machado, que transformará completamente o trabalho agrícola, doméstico, etc. Brutal e violentamente incorporado primeiro à 'encomenda' - exploração gratuita do trabalho indígena - depois aos 'repartimentos', sejam agrícolas ou mineiros (a 'mita' andina), para, finalmente, receber salários de fome nas 'fazendas', o índio deverá recompor totalmente sua existência para sobreviver numa opressão desumana: as primeiras vítimas da modernidade - o primeiro ‘holocausto' moderno, como o chama Russel Thornton” (DUSSEL, 1993, p. 160).
} 
últimas décadas, principalmente a partir da década de 1980, através dos grupos e movimentos organizados em torno da temática.

Vera Maria Ferrão Candau (2013, p. 148) recorda que apesar da realidade dos grupos e movimentos negros ser muito heterogênea e diferenciada América na Latina, é possível afirmar que estes foram grupos, em geral, foram reduzidos a uma posição de não cidadania até a metade do século passado, fazendo-se necessário recordar que o regime de escravidão persistiu em alguns países, como o Brasil, até final do século XIX; porém, em diferentes nações, foram muitas as lutas de grupos afrodescendentes por condições de vida digna e combate à discriminação e ao racismo; tais grupos se têm caracterizado pela resistência e por suas lutas contra o racismo em suas diferentes manifestações interpessoais ao racismo estrutural, assim como pela afirmação de direitos e plenitude da cidadania, o que supõe reconhecimento de suas identidades culturais.

Porém, obviamente, a força do poder econômico, que proporciona outros poderes, como o social, o cultural, o jurídico etc., deu prevalência aos dominantes, sendo que, no caso brasileiro, a escravidão negra chegou ao fim em razão dos próprios interesses mercantis da Inglaterra, interessada em expandir seu mercador consumidor.

As colônias converteram-se num mercado. A população colonial é uma clientela que compra. Por conseguinte, se a guarnição tem de ser eternamente reforçada, se o comércio decai, isto é, se os produtos manufaturados e industrializados não podem mais ser exportados, verifica-se que a solução militar deve ser afastada. Um domínio cego de tipo escravista não é economicamente rentável para a metrópole (FANON, 1968, p. 49-50).

A colonização dos países latinos e o seu braço armado, a escravidão, deixaram marcas que se sentem até hoje nestes países. Sob um discurso jurídico segundo o qual a abolição tornaria dominantes e dominados iguais em direitos, os sujeitos descendentes daqueles que foram escravizados continuam a experimentar um processo contínuo de negação de seus direitos.

No Brasil, por exemplo, o racismo, antes, com forte viés individual, fortalece-se e esconde-se, agora, nas formas institucional e cultural. Ocorre que estas duas últimas formas são muito mais difíceis de serem combatidas, já que, em regras, ocultas, invisibilizadas ou dissimuladas. 
O direito, por sua vez, focou os esforços em combater principalmente as práticas racistas individuais ${ }^{10}$, inclusive atribuindo todo o peso da prática sobre as condutas dos sujeitos, pouco combatendo o racismo institucional e cultural, o que contribuiu para difundir o mito da "democracia racial".

Um bom exemplo disso é a questão do crime de racismo, previsto na Constituição Federal, negligenciando o racismo institucional e cultural11 e punindo fortemente as práticas individuais ${ }^{12}$, sem que tenha proposto ações afirmativas, que só foram levadas adiante em

10 Para combater o racismo individual, a legislação penal apresenta 02 (dois) exemplos de tipificação, o racismo (inscrito na Lei $\mathrm{n}^{\mathrm{0}} 7.716 / 1989$, que define os crimes resultantes de raça ou de cor) e a injuria racial (prevista no Código Penal, Decreto-Lei no $2.848 / 1940$, no art. $140, \S 3^{\circ}$ ).

11 A Constituição dá diretrizes gerais para o combate do racismo institucional e cultural, sem que tenha traçado os instrumentos de combate: Art. $3^{\circ}$ Constituem objetivos fundamentais da República Federativa do Brasil: [...] IV - promover o bem de todos, sem preconceitos de origem, raça, sexo, cor, idade e quaisquer outras formas de discriminação. [...] Art. $4^{\circ}$ A República Federativa do Brasil rege-se nas suas relações internacionais pelos seguintes princípios: [...] VIII - repúdio ao terrorismo e ao racismo;

12 Art. $5^{\circ}$ Todos são iguais perante a lei, sem distinção de qualquer natureza, garantindo-se aos brasileiros e aos estrangeiros residentes no País a inviolabilidade do direito à vida, à liberdade, à igualdade, à segurança e à propriedade, nos termos seguintes: [...] XLII - a prática do racismo constitui crime inafiançável e imprescritível, sujeito à pena de reclusão, nos termos da lei; 
virtude de um grande percurso da luta e reconhecimento ao longo das décadas de 1990 e 200013 .

O despertar dos sujeitos renegados, principalmente negros e indígenas, com suas multifacetadas imbricações identitárias, não é um processo simples, pois lidar com as desigualdades de direitos requer mudanças nas estruturas das instituições públicas e privadas, que continuam a manter práticas institucionais que passaram incólumes aos diversos movimentos constitucionais reformistas.

A tomada de consciência dos negros pelo reconhecimento de seus direitos pressupõe a interculturalidade, que deve favorecer a consciência da própria identidade cultural que, em geral, é dinamizada no contraste com o outro, o diferente; trata-se, dessa forma, de processos imbricados e entrecruzados, sendo importante ter em mente que a interculturalidade deve promover o diálogo em bases igualitárias, e isso não se deve dar como pressuposto e ser favorecido pelo mesmo processo intercultural, emponderando-se os grupos que necessitem de

13 O Estatuto da Igualdade Racial (Lei n $\left.{ }^{\circ} 12.288 / 2010\right)$, a lei de cotas nas universidades e demais instituições federais de ensino (Lei $n^{\circ} 12.711 / 2012$ ) e a lei de cotas para negros no serviço público do Executivo da União (Lei $n^{\circ}$ 12.990/2014) são contemporâneas ao julgamento da ADPF 186, que julgou constitucional o sistema de cotas implantado pela Universidade de Brasília - UnB: Ementa: ARGUIÇÃO DE DESCUMPRIMENTO DE PRECEITO FUNDAMENTAL. ATOS QUE INSTITUÍRAM SISTEMA DE RESERVA DE VAGAS COM BASE EM CRITÉRIO ÉTNICO-RACIAL (COTAS) NO PROCESSO DE SELEÇÃO PARA INGRESSO EM INSTITUIÇÃO PÚBLICA DE ENSINO SUPERIOR. ALEGADA OFENSA AOS ARTS. $1^{\circ}$, CAPUT, III, $3^{\circ}$, IV, $4^{\circ}$, VIII, 5ㅇ, I, II XXXIII, XLI, LIV, 37, CAPUT, 205, 206, CAPUT, I, 207, CAPUT, E 208, V, TODOS DA CONSTITUIÇÃO FEDERAL. AÇÃO JULGADA IMPROCEDENTE. I - Não contraria - ao contrário, prestigia - o princípio da igualdade material, previsto no caput do art. $5^{\circ}$ da Carta da República, a possibilidade de o Estado lançar mão seja de políticas de cunho universalista, que abrangem um número indeterminados de indivíduos, mediante ações de natureza estrutural, seja de ações afirmativas, que atingem grupos sociais determinados, de maneira pontual, atribuindo a estes certas vantagens, por um tempo limitado, de modo a permitir-lhes a superação de desigualdades decorrentes de situações históricas particulares. II - O modelo constitucional brasileiro incorporou diversos mecanismos institucionais para corrigir as distorções resultantes de uma aplicação puramente formal do princípio da igualdade. III - Esta Corte, em diversos precedentes, assentou a constitucionalidade das políticas de ação afirmativa. IV - Medidas que buscam reverter, no âmbito universitário, o quadro histórico de desigualdade que caracteriza as relações étnico-raciais e sociais em nosso País, não podem ser examinadas apenas sob a ótica de sua compatibilidade com determinados preceitos constitucionais, isoladamente considerados, ou a partir da eventual vantagem de certos critérios sobre outros, devendo, ao revés, ser analisadas à luz do arcabouço principiológico sobre o qual se assenta o próprio Estado brasileiro. V Metodologia de seleção diferenciada pode perfeitamente levar em consideração critérios étnico-raciais ou socioeconômicos, de modo a assegurar que a comunidade acadêmica e a própria sociedade sejam beneficiadas pelo pluralismo de ideias, de resto, um dos fundamentos do Estado brasileiro, conforme dispõe o art. $1^{\circ}$, V, da Constituição. VI - Justiça social, hoje, mais do que simplesmente redistribuir riquezas criadas pelo esforço coletivo, significa distinguir, reconhecer e incorporar à sociedade mais ampla valores culturais diversificados, muitas vezes considerados inferiores àqueles reputados dominantes. VII - No entanto, as políticas de ação afirmativa fundadas na discriminação reversa apenas são legítimas se a sua manutenção estiver condicionada à persistência, no tempo, do quadro de exclusão social que lhes deu origem. Caso contrário, tais políticas poderiam converter-se benesses permanentes, instituídas em prol de determinado grupo social, mas em detrimento da coletividade como um todo, situação - é escusado dizer - incompatível com o espírito de qualquer Constituição que se pretenda democrática, devendo, outrossim, respeitar a proporcionalidade entre os meios empregados e os fins perseguidos. VIII - Arguição de descumprimento de preceito fundamental julgada improcedente. (ADPF 186, Relator(a): Min. RICARDO LEWANDOWSKI, Tribunal Pleno, julgado em 26/04/2012, ACÓRDÃO ELETRÔNICO DJe-205 DIVULG 17-10-2014 PUBLIC 20-10-2014) 
uma maior afirmação de sua identidade, para que a igualdade possa ser construída e afirmada na mesma interação intercultural (CANDAU, 2013, p. 156).

Enrique Dussel (2015, p. 130-131) deixa claro que a incorporação de "novos" direitos ao "sistema do direito", ou a explosão do "sistema do direito" vigente, que agora se transforma em "antigo", por um novo sistema do direito, é fruto não tanto da explicitação de um direito natural, contudo não descoberto, e sim da institucionalização de um "novo" direito descoberto pelas vítimas "sem-direito", fruto da maturidade histórica própria ao desenvolvimento da realidade humana (e da consciência política), do processo civilizatório da comunidade política particular ou da humanidade em geral.

Esse processo de descoberta, "descobrimento" ou reconhecimento de novos direitos pelos sujeitos renegados não é fruto nem de um estudo teórico nem de um voluntarismo de certos movimentos messiânicos; é fruto da consciência crítico-política dos grupos que sofrem os efeitos negativos do estado-de-não-direito de uma dimensão humana que a maturidade histórica desenvolveu, mas que o direito não incluiu, contudo, como exigências que requerem institucionalidade pública (DUSSEL, 2015, p. 131). Portanto, com a tomada de consciência dos sujeitos renegados, é possível a construção ou reconstrução do direito, que não seja mero instrumento de dominação e forma de mascarar os racismos institucional e cultural; as questões raciais devem ser discutidas e amplamente debatidas, a fim de que as amarras institucionais do passado venham a lume, única forma de destruí-las e de se construir um Estado de Direito efetivamente igualitário, capaz de proporcionar oportunidades e direitos a todos e não somente àqueles que se valem das estruturas estruturantes para manter seus privilégios.

\section{CONSIDERAÇÕES FINAIS}

$\mathrm{O}$ artigo procurou relacionar colonialismo e o racismo como expressões da estrutura de dominação decorrente da Modernidade, pois havia necessidade de que fossem criadas distinções entre os humanos capazes de sustentar as diferenças econômicas: a criação de teorias jurídicas para sustentar tal empreitada foi essencial. 
O trabalho, inicialmente, parte das já conhecida teoria a respeito do colonialismo e do racismo a partir de Jean-Paul Sartre; na visão do filósofo, para que o colonialismo se mantivesse como sistema econômico, era essencial a prática do racismo, inscrito nos próprios fatos, nas instituições, na natureza das trocas e da produção; os estatutos político e social se reforçavam mutuamente, dando feição sub-humana aos sujeitos subalternos dominados (negros e indígenas), já que as declarações de direitos não lhes diziam respeito. Ainda, para Jean-Paul Sartre, o racismo, engendrado pelo aparelho de dominação colonial, foi mantido pelas relações de produção que definiram duas espécies de sujeitos: para uns, privilégios e a humanidade, homens livres no exercício de seus direitos; para demais, "os outros", a ausência de direitos e a sanção pela miséria, a fome crônica, a ignorância e a sub-humanidade.

O combate ao racismo deve levar em consideração que o mesmo é um fenômeno complexo, podendo se dar de forma individual (relação entre indivíduos), institucional (relação e instituições e os sujeitos) e culturalmente (ideia de uma suposta superioridade cultural afirmada por determinadas categorias de sujeitos). O enfoque do trabalho se deu nas duas últimas formas, principalmente na forma cultural.

No ponto acima, um dos elementos de dominação colonial residiu na dominação dos elementos culturais dos povos dominados, principalmente, nos campos religiosos e da educação, o que traz consequências que são experimentas até hoje. Como em qualquer processo de dominação, devem os sujeitos oprimidos tomar consciência do processo de dominação, devendo negras, negros e indígenas, para serem reconhecidos, serem afirmados, o que passa por um processo de auto-reconhecimento, baseado em políticas públicas de educação, saúde, cultura etc., pensadas em perspectiva histórica que reconheça as lutas dos oprimidos, sendo um exemplo disso o tema da demarcação das terras indígenas e da titulação das terras quilombolas, que constituem tarefa importante para o aprofundamento da estratégia de afirmação das identidades, em prática constitucional capaz de refundar o sentido de Modernidade.

Todavia, como é possível romper com essa lógica de dominação? Como os saberes proporcionados pelas Ciências Sociais podem alicerçar mudanças baseadas em uma sistemática jurídica de reconhecimento e de empoderamento? No caso da América Latina, muitas das respostas não serão encontradas apenas na mera repetição das ideias vindas do Norte, seja da Europa ou dos Estados Unidos. Conquanto não se deva desconsiderar a 
produção desse conhecimento, deve-se ter em mente que é possível se construir uma epistemologia que envolva a historicidade e a realidade que impera nesta parte do continente.

Com a crise do Estado de Direito, surgem fissuras que permitem se questionar e construir novos direitos, a partir de uma epistemologia própria. Dessa maneira, os estudos sobre decolonialidade têm avançado e a partir deles dos mesmos têm surgido novas formas de se interpretar a história universal e local, levando-se, por exemplo, à compreensão de determinados fenômenos jurídicos e suas implicações nas estruturas sociais dos países em desenvolvimento, como ocorre na América Latina, especialmente no Brasil, foco deste trabalho.

Romper com um modelo de colonialidade requer uma consciência do papel da ciência, inclusive das Ciências Humanas e Sociais Aplicadas, e, nesse particular, o Direito. Assim, não é possível falar em mudanças sociais sem se pensar em mudanças nas relações jurídicas, forte fator de estruturação da engenharia institucional latino-americana.

O despertar dos sujeitos renegados, principalmente negros e indígenas, com suas multifacetadas imbricações identitárias, não é um processo simples, pois lidar com as desigualdades de direitos requer mudanças nas estruturas das instituições públicas e privadas, que continuam a manter práticas institucionais que passaram incólumes aos diversos movimentos constitucionais reformistas.

Com a tomada de consciência dos sujeitos renegados é possível a construção ou reconstrução do direito, que não seja mero instrumento de dominação e forma de mascarar os racismos institucional e cultural; as questões raciais devem ser discutidas e amplamente debatidas, a fim de que as amarras institucionais do passado venham a lume, única forma de destruí-las e de se construir um Estado de Direito efetivamente igualitário, capaz de proporcionar oportunidades e direitos a todos e não somente àqueles que se valem das estruturas estruturantes para manter seus privilégios.

\section{REFERÊNCIAS}

ÁVILA SANTAMARÍA, Ramiro. El neoconstitucionalismo transformador: el Estado y el derecho en la Constitución de 2008. Quito: Abya Yala, 2011. 
ARANTES, Marco Antonio. Sartre e o humanismo racista europeu: uma leitura sartriana de Frantz Fanon. In: Sociologias, Porto Alegre, ano 13, nº 27, mai./ago. 2011. p. 382-409.

BOURDIEU, Pierre; WACQUANT, Löic. A astúcia da razão imperialista. In: O mistério do ministério: Pierre Bourdieu e a política democrática. Tradução de Paulo Cezar Castanheira. Rio de Janeiro: Editora Revan, 2005, p. 209-230.

CANDAU, Vera Maria Ferrão. Educación intercultural crítica: construyendo caminos. In: WASH, Catherine (org.). Pedagogías decolonialies: práticas insurgentes de resistir, (re)existir y (re)vivir. Quito: Abya Yala, 2013, p. 145-161.

CUEVAS MARÍN, Pilar. Memoria colectiva: hacia un proyecto decolonial. In: WASH, Catherine (org.). Pedagogías decolonialies: práticas insurgentes de resistir, (re)existir y (re)vivir. Quito: Abya Yala, 2013, p. 69-104.

DUSSEL, Enrique. 1492. O encobrimento do outro: a origem do "mito da modernidade". Tradução de Jaime A. Clasen. Petrópolis: Vozes, 1993.

. Direitos humanos e ética da libertação: pretensão política de justiça e a luta pelo reconhecimento dos novos direitos. In: Revista InSURgência, Brasília, ano 01, v. 1, $\mathrm{n}^{\mathrm{o}} 01$, jan./jun., 2015. p. 121-135.

FANON, Frantz. Os condenados da terra. Tradução de José Laurênio de Melo. Rio de Janeiro: Civilização Brasileira, 1968.

EDUFBA, 2008.

. Pele negra, máscaras brancas. Tradução de Renato da Silveira. Salvador:

JONES, James M. Racismo e preconceito. Tradução de Dante Moreira Leite. São Paulo: Editora Da Universidade de São Paulo, 1973.

LANDER, Edgardo. Ciências Sociais: saberes coloniais e eurocêntricos. In: LANDER, Edgardo (Compilador.). La colonialidad del saber: eurocentrismo y ciências sociales. Perspectivas latinoamericanas. Buenos Aires: CLACSO, 2005, p. 21-53.

MIGNOLO, Walter D. (Editor). Local histories/global designs: coloniality, subaltern knowledges, and border thinking. Princeton: Princeton University Press, 2000.

OSTERHAMMEL, Jürgen. Colonialism: a theoretical overview. Translated from German by Shelley L. Frisch. 2. ed. Princeton: Markus Wiener Publishers, 2005.

REVATHI, Krishnaswamy; HAWLEY, John C. (Editors). The postcolonial and the global. Minneapolis: University of Minnessota Press, 2008.

SARTRE, Jean-Paul. Orfeu negro. In: Reflexões sobre o racismo. Tradução de J. Guinsburg. 5. ed. São Paulo: Difusão Europeia do Livro - DIFEL, 1968, p. 89-125.

. Colonialismo e neocolonialismo. Tradução de Diva Vasconcelos. São Paulo: Tempo Brasileiro, 1968. 
QUIJANO, Anibal. Colonialidade do poder, eurocentrismo e América Latina. In: A colonialidade do saber: eurocentrismo e ciências sociais. Perspectivas latino-americanas. Edgardo Lander (org). Buenos Aires: CLACSO, 2005, p. 227-278.

WALSH, Catherine. Introducción. Lo pedagógico y lo decolonial: entretejiendo caminhos. In: WASH, Catherine (org.). Pedagogías decolonialies: práticas insurgentes de resistir, (re)existir y (re)vivir. Quito: Abya Yala, 2013, p. 24-68. 